This is the peer reviewed version of the following article: Ross, Wendy and Vallée-Tourangeau, Frédéric (2021) Microserendipity in the creative process. Journal of Creative Behavior, 55(3), pp. 661-672. , which has been published in final form at https://doi.org/10.1002/jocb.478. This article may be used for non-commercial purposes in accordance with Wiley Terms and Conditions for Use of Self-Archived Versions. This article may not be enhanced, enriched or otherwise transformed into a derivative work, without express permission from Wiley or by statutory rights under applicable legislation. Copyright notices must not be removed, obscured or modified. The article must be linked to Wiley's version of record on Wiley Online Library and any embedding, framing or otherwise making available the article or pages thereof by third parties from platforms, services and websites other than Wiley Online Library must be prohibited 


\title{
Microserendipity in the Creative Process
}

Wendy Ross and Frédéric Vallée-Tourangeau

Kingston University

\author{
Author Note
}

Address correspondence to either Wendy Ross, Department of Psychology, Kingston

University, Penrhyn Road, Kingston upon Thames, KT12EE, UNITED KINGDOM;

w.ross@kingston.ac.uk. We would like to thank Ron Beghetto, Samantha Copeland, Vlad

Glăveanu, Paul March, and two anonymous reviewers for helpful comments on earlier drafts. 


\section{Microserendipity in Creative Process}

The puzzle facing those who research creativity is how to pinpoint the genesis of a new idea. Traditional cognitivist approaches have implicitly assumed a linear process with an internal locus of idea generation which proceeds and directs engagement with materials (Glăveanu, 2014; Ingold, 2009). This reflects a wider research tendency which loads the responsibility for creativity on the individual person and seeks the answer to great creativity in the mind of a creative genius (Ross \& Vallée-Tourangeau, 2018). Despite notable exceptions and objections (Csikszentmihalyi, 1999; Glaveanu, 2014; Montuori \& Purser, 1995; Sawyer, 2010) to this framework, laboratory based investigations into how new thoughts are formed tend to make the assumption that the focus of study should be the internal mechanisms and individual psychometric properties undergirding creativity. In this way, studies of eminent creators focus on their biographical details (see for example, Steptoe, 1998) and laboratory-based studies of creative cognition focus on participants' responses to problems designed to elucidate internal cognitive processes. Thus, participants may be presented with an insight problem - that is a problem which is not amenable to strategic processing but is rather solved by an abductive leap - and their success rate calculated and latency to solution recorded. These tasks are presented in such a way as to require and therefore isolate mainly mental processes (such as a riddle or a pictorial representation of a problem, see Vallée-Tourangeau, 2014).

This paper will argue that this classical view of how creativity unfolds does not fully reflect qualitative reports of creativity whether in the lab or the artist's atelier where the internal genesis of a creative thought cannot be separated from its external expression. These qualitative studies describe a dynamic and situated process; a framework of creativity that extends the unit of analysis beyond a purely internal view is necessary to fully incorporate this evidence from different theoretical and empirical perspectives. Ignoring how participants 
may recruit and exploit external physical resources in thinking not only prevents researchers from mapping the physical traces of the genesis of a new idea (Vallee-Tourangeau \& ValléeTourangeau, 2020) but also necessarily excludes those moments when the material is a constitutive part of that process. In this paper we argue that the role of unplanned accidents has been under researched and propose the relational concept of serendipity to support the explanation of how creativity emerges from the interaction of external accidents and internal psychometric properties. We first proceed by reviewing ideas and evidence that underscore the importance of materiality in creativity. Taking material engagement as the vantage point of a perspective on creativity casts agency and accidents in a challenging light; challenging in that materiality invites a distributed definition of agency and at the same time elevates the ontological status of accidents not as anecdotal events that favour a prepared mind- to paraphrase the oft-quoted Pasteurian aphorism - but as the inevitable consequence of creative agents physically manipulating the world qua thinking or creating. We then proceed to contrast more sharply the concept of 'luck' and the notion of 'serendipity'; the later requires an enacted coupling with the physical environment. We are then in a position to define and illustrate the concept of 'microserendipity' more rigorously, and in the process outline methodological recommendations to help researchers better understand this phenomenon in the genesis of creative thought.

\section{Creative Material Engagement}

It is not surprising that when the research focus is on the individual properties that generate a creative product, then it provides strong evidence for the role of these traits. Methodologies are not epistemologically neutral (Vallée-Tourangeau \& March, 2019). However, if we move beyond laboratory based studies of creativity and assess the rich empirical data from semi-structured interviews or case studies, these provide supporting 
evidence for a model in which the material environment is not accepted as a passive scaffold for creativity but actively shapes the process (Malafouris, 2020).

For instance, the work of Glăveanu et al. (2013) challenges this person-centred notion of creative agency across broad range of creative domains: artists, designers, science, writers and musicians. What emerges from the results of their series of interviews is a collaborative tension between human and material agency. The artists interviewed suggest that "objects resist the intentions of the artist. All of a sudden, objects 'ask a question' and very often 'change the original plan,' being 'stronger' than the creator, 'imposing their rules'.” (p. 5). Designers spoke of a collaborative relationship with the materials "from the need to explore materials, to 'test their limits', to the frustrations one experiences when not 'feeling' the fabric" (p. 7). Even the chemist (not a domain traditionally associated with material play) described their creative process in terms of a "game with matter" (p. 8).

Similar descriptions of material agency arise in the description of an artist arranging photos in Sjöholm (2014), where the final work is described as "a hybrid of the artist and the physicalities of the collected" (p. 510). The artist further "explains how the photos were asking to be categorized in a different way" (p. 509). Equally, the qualitative work undertaken by Glăveanu (2012) on the decoration of Romanian Easter eggs indicates that creativity is distributed between the maker and the material affordances of the eggs themselves where the affordances are initially 'unperceived' but will go on to shape the final product once noticed. This engagement with the material can cause uncertainty and it is this uncertainty which may spark the genesis of the idea (Bardt, 2019; Beghetto, 2020).

Such results foreground the importance of the material in creativity and invite a more nuanced characterisation of agency than traditional linear models (Malafouris, 2014). Although there have been several calls to recentre the material in our understanding of human behaviour and cognition (Barad, 2003; Orlikowski, 2007), it is perhaps particularly surprising 
that the relationships with the material is under emphasised in creativity research (Tanggaard \& Beghetto, 2015) where there is a necessary entanglement with material; to create is to produce something concrete, the ephemerality of a novel thought moves from imagination to creativity when it is enacted and not before. We align ourselves with those researchers who suggest that creative processes are constituted not by internal computations over mental representations of the artist's materials but through and by those materials (see also Bardt, 2019; March, 2019; Glăveanu, 2020; Wheeler, 2018). This is not to suggest that internal processes are erased but rather that they are manifest through the act of creating and it is this act which is necessarily engaged with material.

This material engagement is what Malafouris (2020) calls 'thinging': "things actively participate in human cognitive life" (p. 2). In the case of creativity, he argues that creative agency cannot be reduced to one or other part of the relationship between the maker and the material, rather it arises from the dance between the two; in other words, it is irreducible to either a mental or physical cause. Malafouris supported his ideas with detailed qualitative observations of the potter at the wheel to illustrate how observing the process of making collapses an artificial distinction between imagination and formation. Detailed qualitative observational data such as this allows us to enhance our understanding of complex creative processes and draw out more elusive mechanisms.

If we expand the creative ecosystem to encompass the objects and people who play an active role in the creative process, then we move from a linear, staged theory of creativity in which an internal plan is imposed on inert matter and the final product is what mattershylomorphism as per Ingold (2009) — to a looping and reciprocal process from which agency emerges. Such a model suggests that what is produced cannot be explained by a reductive process that focuses on only the properties of one or the other, but rather must take into account the manner in which a creative moment emerges from their interaction. This 
dynamic, action-based account of creativity invites tracking the smaller, micro moments that arise in the sometimes-mundane practice of artistic creation (Beghetto, 2009; Tanggaard \& Beghetto, 2013).

\section{The Role of Accidents}

When material objects are considered active agents in the creative process, it is often done so with a discussion of their affordances for action. We follow Chemero (2011) who argues that affordances are not static properties of an object but instead emerge through interaction and cannot be reduced to either of the two agents; rather they are relational (Glăveanu, 2020). How this interaction unfolds is necessarily complex. However, in the following sections, we show that accidents arising from the unplanned actions explain some of that complexity. This is not intended as a comprehensive explanation of all creative mechanisms, but rather a suggestion to expand the theoretical register.

Video recordings of participants engaged in a problem-solving task allow us to trace this shifting agency as it unfolds on a microscale. Consider Steffensen et al. (2016) who undertook a frame by frame analysis of an insight problem solver in a materially rich environment. The original study invited participants to place 17 animals in four enclosures such that there is an odd number in each enclosure. The solution to this difficult problem requires abandoning the direct application of an arithmetic solution—no four odd numbers can add to 17 - and creating overlapping pens. In their detailed analysis of a single problem solver who worked on building a physical model of the solution (with pipe cleaners and animal figurines), the authors show that the pivotal change in the problem solving trajectory arose from an accidental overlap of the enclosures (the chenille material of the pipe cleaners crocheted one enclosure onto another). An accidental move and change in the environment offered and interesting interim configuration which was then distilled by the participant into a solution. This observational data suggest an important place for the role of accident in 
problem solving, captured in laboratory conditions while participants engaged in first order problem solving, that is when they think through and with a physical model of the problem (Vallée-Tourangeau \& March, 2019). It is thus possible to document the role of accidents in the origins of new ideas under laboratory conditions.

Outside the laboratory, qualitative ethnographic accounts of creative cognition are replete with accidents. Sjöholm (2014) casts accidents as a mechanism through which the photographs disrupt the artists' creative plan: "the photos kept on being uncontrollable in the sense that they kept on falling down to the floor" (p.509). For the artists interviewed by Glăveanu et al. (2013) "accidents enrich the project and one needs to constantly be on the alert for them' (p. 5) for designers 'creative activity is a game [...] of 'happy' accidents” (p. 7), for scientists: "there is in science room for accidents and surprises" (p. 8) and for musicians: "accidents play also a role in this process, and they are 'artistically interesting to have"” (p. 11). The role of accidents in the creative process was also emphasised as a key emergent theme by Sawyer (2018) in his qualitative work on the creative processes of MFA students: "artists described a moment in their creative process when an unexpected accident, originating in the external environment, contributed to their creative process." (p. 134).

The role of accident in the creative process is explicitly considered by Piñeyro (2019) when she explores the process of creating polymeric coiled actuators, a form of nylon coil to incorporate into woven and knitted textiles. An accident during the creative process - too much weight applied to the lower end of the coil—created a new structure and facilitated new understanding of the kinetic potential of the material. The accident led to changes on both a local scale within the nylon coil itself and also on a more global scale as it elicited change in the whole research project: "the accidental event influenced the methods subsequently used in the research" (p. 1879).

\section{The Problematic Role of Luck}


It would be disingenuous to suggest that the role of luck generally is ignored in creativity research. Indeed, it is often explicitly cited as important to the creative process (Csikszentmihalyi, 1996; Simonton, 2004). However, luck in these accounts tends to be conceived of as a lifelong factor. Simonton's (2004) research on creativity in science focuses on chance not just in the generation of new ideas but also in how chance functions in all aspects of the new ideas being realised from peer review to grant funding with the statement that the "the chance account accommodates more fully the immense complexity of scientific creativity" (p. 163). In this way, we make a distinction between broader stories of luck in personal narrative and smaller microgenetic moments at the moment of material engagement which we call accidents. When artists refer to accidents, they also mean the smaller moments of tension and rupture that shape particular moments in the creative process, like the accidents described by the creative professionals interviewed above. Thus, luck is heteroscalar: that is, it has an influence on multiple time scales. Of these, the micro scale is often referenced in passing but remains under investigated.

Of course, all types of luck from accident to fortunate coincidences are problematic in the case of creativity. Creativity in the research literature and in popular understanding has acquired the status of an epistemic and character virtue (Kieran, 2017; Weisberg, 2015) whether that be a virtue associated with a unique talent or with the level of perseverance and hard work. If creativity is considered a virtue, then it must be agential and not overly dependent on chance. Weisberg is particularly dismissive of accidents in creativity. He repeatedly (e.g., 2006, 2010, 2015) caricatures accidents in creativity with the following story: "Let us say that I am a painter, and one day I accidentally spill paint on a canvas, which leaves a stain on my partially finished work, making it unusable. Let us further assume that I am visited by the director of a museum, who sees my stained canvas, loves it, and purchases it for display in the museum. The painting is then discussed in art books, and other 
artists use my spilled work as the basis for innovations of their own. My piece of junk has thus become part of the world of art. Was I creative in producing that painting? No (...)" (2006, p. 60, emphasis added). Weisberg also juxtaposes this story with a schizophrenic's "word salad" (2010, p. 237): While the canvas with spilled paint and the psychotic word salad can be novel, neither can be deemed creative because of their unintentional origin. Intentionality is a key feature of Weisberg's definition of creativity. To be sure, accidents problematize agency and intentionality in creativity. Weisberg $(2015$, p. 121) goes on: “(...) it is possible to obtain objective evidence for the intentionality of some action. Suppose that one was observing the artist who knocked over that can of paint. If she said "'Oops!' as the can went over, one would have evidence for a lack of intentionality in the action." But the artist might have said "Aha" rather than "Oops", and it is these micro moments of 'insight' or possibly 'outsight' (Vallée-Tourangeau \& March, 2019) that can pave the trajectory of a creative product. It is Weisberg's implicit commitment to an internalist model of creativity that endows his spilled paint anecdote the force he believes it conveys. A transactional perspective on creativity, however, shreds Weisberg's anecdote of much of its rhetorical value.

However, there is an underlying anxiety expressed here that recurs across the literature. Bardt (2019, p. 91) expresses the same fear: "At its worst, chance is an inauthentic, unearned creativity". It is clear that to suggest that accident plays a part in creativity does appear to undermine the very real need for talent and training which is integral to the artistic process (Blackburn, 2017). The challenge then is to incorporate the very real reports of accident into the model of creativity without risking creativity becoming perceived as a stochastic process, landing at random. Rather than viewing accident only through the framework of non-agentic chance (Coffman, 2009), this paper suggests that the framework of serendipity can elucidate the balance between unplanned environmentally generated actions 
and personal agency and talent. On this view, creative intentionality and agency emerge through enacted luck.

\section{From Luck to Serendipity}

Since Walpole (1754; Merton \& Barber, 2004) coined the word serendipity there has been debate over the exact meaning and different writers and domains have explored different aspects of the word (Napolitano, 2013). Simply put, serendipity arises when there is a combination of accident and sagacity, occurring "at the intersection of chance and wisdom" (Copeland, 2019, p. 2385), and therefore it cannot be understood without reference to both chance and wisdom. Wisdom here is best understood not as a psychometric property that can be profiled ${ }^{1}$, but rather as describing the process of enacting the luck which is constantly generated by an environment in flux. Serendipity occurs through action. In this way, serendipity properly understood collapses the distinction between luck and wisdom: serendipitous wisdom arises when luck is enacted. This echoes Piñeyro's recognition that her attitude towards the accident and her "intuitive, improvisational and open-ended" method of working (p. 1880) represented a sagacity that reflects broader creative practice and play (see also Austin's [1979] notion of 'altamirage'). Whereas a narrative based around artistic talent places agency in the artist and one based around luck places agency in the environment, serendipity suggests that agency and creative intention arises in the relationship between the two.

In addition to the relational aspect, serendipity has a contingent aspect. While luck must be enacted to become serendipity, the same combination of accident and sagacity is not always sufficient to guarantee these moments. Rather, there is a vexing temporal contingency. This leads to a complex phenomenon, yet one which deserves further unpacking. It is important to note, for instance, that in the case of the controlled and detailed

\footnotetext{
${ }^{1}$ Indeed, attempts to do have led to frustrating results; see McCay-Peet, Toms, and Kelloway (2015).
} 
observations of the 17A participant in Steffensen et al. (described above), accidental overlaps occurred previous to the event trigger, and so failed to be enacted. These moments of 'missed serendipity' occurred with the same person in the same environment, but there was a singular moment in which the individual was able to exploit the environmental affordances offered by the accident. Serendipity here was the property of the moment rather than only the person and situation. This contingency on a temporal moment reflects its emergent nature. These factors make a predictive research programme more problematic. However, the lack of predictability is not a strong enough reason to ignore its existence, nor does it undermine its importance in unveiling its role in the creative process. When dealing with something as complex and singular as creativity, it is perhaps important to bear in mind that non predictive explanations of singular events hold equal validity (Robinson, 2011; Sutton, 2010).

As a young research field, there have been several models proposed to explain the process of serendipity. What is remarkable about these models is their similarity in form to models of insight problem solving (e.g., Danek, 2018): They posit a change in the internal disposition of the problem solver often accompanied by a phenomenological marker, which is indistinguishable from the 'aha' moment in insight research. This points to an already close although under explored relationship between serendipity and current models of insight. Makri and Blandford (2012) suggest that to make the connection, a necessary part of their model of serendipity, requires a moment of 'insight'. Later Makri argues that the shift in thinking observed in serendipity where the external world becomes a catalyst for change and forces new connections which could not possibly be anticipated is the same as the shift in thinking observed in innovation and creativity (Race \& Makri, 2016). In the model Race and Makri propose, serendipity is responsible for innovation in part because it forces a changes in the course of action. McCay-Peet and Toms (2015) describe serendipity 'triggers' which could easily be recast as the 'hints' that have been seen to facilitate insight problem solving 
(Ball \& Litchfield, 2013). When Foster and Ford (2003, p. 330) write of serendipity "taking the researcher in a new direction, in which the problem conception or solution is reconfigured in some way", there are palpable echoes of the restructuring theory that accompanies models of insight (Ohlsson, 1992).

The main difference between the two is that insight problem solving has traditionally been cast as a purely internal process (although see Vallée-Tourangeau, [2014] for a critique of this research programme) whereas there has always been a necessary emphasis in the serendipity literature on a bidirectional, materially engaged aspect of serendipity that reflects its emmeshed nature. So, in contrast to insight research where restructuring is theorised as coming about through unconscious semantic inferences that link hitherto unrelated elements in the mind of the problem solver (Ohlsson, 1992), the links and restructuring in serendipity research is driven by chance and accidents arising in the environment. In this way, it is closer in form to insight generated through material manipulation (Vallée-Tourangeau et al., 2016) or data driven restructuring (Fleck \& Weisberg, 2013), both of which open up a space for the external world in the creative ecosystem.

In summary, qualitative accounts of creativity challenge the dominant drive in research on creativity in two important ways: They centre material agency and consequently naturally invite reflections on the role of accident in the creativity. The presence of small moments of luck arising from unplanned changes in the material environment, rather than life-long career-based luck, remain under researched. In part, they are problematic because they undermine creative intentionality, however by recasting these accidents as relational serendipity we can explore how creativity emerges from an interaction between the person, the material and the moment.

\section{Microserendipity}


However, just as with creativity, our understanding of serendipity does not precede methodological considerations. Serendipity is identified after it has occurred, sometimes even after a significant amount of time has elapsed (Foster \& Ellis, 2014). Data are gathered in two main ways: either semi-structured interviews (Erdelez et al., 2016; Makri \& Blandford, 2012; McCay-Peet \& Toms, 2015) or collections of reports of serendipity in either the first or third person (Van Andel, 1994; Yaqub, 2018). If serendipity is researched using retrospective narratives, then the person's understanding of serendipity is centred and directs our own understanding of it (cf. Glaveanu et al. [2011] on creativity). Methodologies are never epistemically neutral and so researching in this way results in a self-reinforcing methodological circle (Danziger, 1985).

It is clear from the qualitative research on creativity that serendipitous moments occur on multiple time scales and with different effects, and that materially generated serendipity is viewed as integral to the creative process across the spectrum of creativity from so-called 'insight' problems as investigated by cognitive psychologists (Steffensen et al., 2016) to creativity as manifested in the creation of large sculptural installations (March, 2019). Such moments are often missed in studies which focus on either the creative product or the creative process over a coarsely grained time scale and through a narrative lens which centres human experience and agency (often a secondary consequence of the language employed to narrate the creative arc of a work of art; Vallée-Tourangeau \& March, 2019).

\section{[INSERT FIGURE 1 ABOUT HERE]}

Rubin et al.'s (2011) model (see Figure 1) generated from their analysis of blog posts suggests that serendipity has three facets: a prepared mind, an act of noticing, and chance. These relate to the personal qualities, the process of turning luck into serendipity, and environmental affordances. Luck in their model is experienced as a "perceived lack of 
control". This echoes the phenomenological description of creatives cited above who report loss of agency when engaging with the material world.

Note that in the model above, chance is not isolated in occasioning the fortuitous outcome. The environment creates lots of opportunities for chance, but that chance is inert until a person acts upon it. As we can see Facet B - the act of noticing - explicitly links the prepared mind and the accident in the environment. This is a contingent moment which is not guaranteed (Ross \& Vallée-Tourangeau, 2020; under review) and it may be that a closer attention to the nature of the act would reveal more about the nature of the prepared mind. For instance, it appears that increased attention to irrelevant objects in the environment predict creative outcomes (Agnoli et al, 2016) and a state of actionable uncertainty (Beghetto, 2020) may increase the likelihood of looking for resolution outside an internal cognitive ecosystem. Additionally, Thrash and Elliot's (2004) detailed psychometric mapping of the traits that relate to inspirational triggers (among which we may count accidents) suggest that the trait of receptive engagement may be strongly related to the feeling of inspiration. However, such explanations require us to take the engagement with materials seriously. Serendipity is something that emerges in action. For those who are concerned that allowing accident a causal role (no matter how small) in creativity somehow threatens it (Weisberg, 2015) or undermines its status as a virtue, a model that requires the accident to be enacted should act as a form of reassurance. Alongside, the environmental opportunities, serendipity is dependent on both a person's actions and state: the act of a person noticing it, which is also dependent on the state of being prepared. The combination of intentional action triggered by accidents in the environment offers a powerful and wider explanatory model for engaged creativity. Neither individual nor environment are privileged in this model, rather their interaction and the distributed nature of artistic agency is what drives the emergent creative product. Serendipity is thus emergent and distributed. 
We term microserendipity, the small moments of serendipity that occur over a controlled time span and are revealed through finer-grained observational methods (such as Kinenoetic Analysis as described in Ross \& Vallée-Tourangeau, in preparation). They may be trivial, or pivotal to the final product, but they form an important part of the process. These micromoments of a creative trajectory deserve recognition and mapping (Tanggard \& Beghetto, 2013). These are similar in nature to moments described by the same term in Bogers and Björneborn (2013). The difference in the understanding of microserendipity proposed here is not the scale of the serendipitous moments but rather the nature of the evidence being collected. Bogers and Björneborn collected reports of serendipitous moments via Twitter. The main distinction between the moments is a methodological one - the moments identified by Bogers and Björneborn are reliant on self-reports, we suggest that we can observe those moments. This does also have ontological implications for serendipity and re-positions it as something than has an existence beyond the understanding of the person who experiences it Such moments have been relatively ignored by research in both creativity and serendipity, but the indirect evidence cited above indicates that they have an important role to play in the creative process.

\section{Towards Developing a Programme of Research in Microserendipity}

It is in many ways not surprising that serendipity remains under-investigated despite being often referenced in passing. It is a "slippery" (Makri \& Blandford, 2012, p. 684) and contingent concept which arises from an unplanned interaction between person and environment and will therefore be inconsistent and complex. Subjecting such a phenomenon to a systematic empirical investigation is fraught with difficulty. However, it is mentioned with sufficient frequency in the creativity literature to warrant taking the time to assess its importance in the creative process. Complexity should not deter efforts to better understand a phenomenon; rather, it should catalyse them. 
The methodology outlined below assumes a commitment to creativity not as a psychological trait but as an action which arises from engagement with a material and can therefore be evidenced through actions and material traces. Such a moment cannot be reliably elicited in the lab nor narrated in retrospect. It is unclear to what extent it is related to personality traits. In our view, microserendipity is a singular, enacted event. We suggest the use of video material to track in detail the creative process (similar to the methods outlined in Tanggaard \& Beghetto, 2015) with at times a frame by frame analysis to pinpoint the shifts in a creative ecosystem (Schubert, 2013). This research could be done across larger data sets, which would allow the frequency of occurrence to be understood and mapped. This is similar in nature to the work and methods outlined in Glăveanu and Lahlou (2012) who describe the use of Subjective Evidence-Based Ethnography (Lahlou, 2011) to track participants' actions as well as thoughts. Such a method would isolate moments of accident. Equally, when it comes to an idiosyncratic artistic process. it would be possible to use this detailed analysis to track moment of serendipity within the trajectory of creativity. A focused ethnography (Knoblauch et al., 2013) of this type would allows moments of broader serendipity to be reconciled with smaller moments of accident to disentangle their role in turning material into art.

For example, participants in Ross and Vallée-Tourangeau (2020) were filmed as they interacted with 7 letter tiles in a Scrabble-like task: They were given 5 minutes to generate as many words of 3 or more letters and were invited to move the tiles to help them discover new words. Performance in this task environment is determined by the participants' verbal fluency as well as the degree to which they engage with the environment, that is the proportion of time they interact with the tiles. The physical reification of new words in this manner is sometimes the product of strategic movements, but a finer-grained analysis of actions, letter configurations and word recognition reveals moments of microserendipity: When 
environmentally generated chance yields a word that is recognized by the participants. This recognition triggers new moves that enact a change in the pathway to the problem solution.

Ross and Vallée-Tourangeau (under review) employed a mixed method procedure to explore anagram solving: Participants were invited to solve 5-letter anagrams with movable letter tiles. They were recorded in an observation lab (equipped with overhead cameras, see Figure 2). Performance was assessed in conditions where participants could shuffle the tiles, but not rearrange individual letters or could shuffle and move the tiles as they saw fit. Aggregate performance measures were calculated, supplemented with detailed coding of the video evidence. Anagrams provide a convenient platform for the study of luck in an interactive environment where letter tiles can be physically moved. Shuffling the letter tiles can yield the problem solution or at least steps toward it. The difficulty of an anagram depends to some extent on distractor bigrams, so shuffling may be crucial for breaking mental set. In addition, letter tiles are easily traceable and identifiable and their movements can be mapped, physically, unveiling the letter configurations that result in solutions, or equally important, that mislead participants. From an observer's perspective, these physical traces also revealed missed moments of serendipity. Thus, the procedure offers a unique opportunity to assess the role of luck and serendipity in problem solving.

\section{[INSERT FIGURE 2 ABOUT HERE]}

The granular coding of the video evidence revealed several moments of microserendipity, that is when moves by the problem solver trigger unexpected configurations in the array which are then noticed and used to direct the problem-solving trajectory. For example, one participant working on the LYMIK anagram, first spells out the word MILK and once this is formed, she notices the left-over Y and uses it to create the solution, MILKY. Her voice rises in pitch in excitement and the move which attaches the $\mathrm{Y}$ is faster than the previous slightly laboured spelling out. The solution is triggered by a change 
in the array rather than a preformed plan. Ross and Vallée-Tourangeau provide other examples of event pivots triggered by an unplanned change in the array.

Such moment of microserendipity can only be captured through a fine-grained analysis of video recording of a participant engaging in problem solving with a physical model of the problem (see the detailed movement by movement analysis reported in Ross \& ValléeTourangeau, 2020; under review). Laboratory research on microserendipity is predicated on a methodological shift from second order problem solving which disconnects the problem solver from her environment, to one that situates the problem solver in a materially rich environment (Vallée-Tourangeau \& March, 2019). It also requires a shift from a focus on aggregate performance measures to the process of problem solving and invention. A more idiographic approach through mixed methods will allow us to document the role of microserendipity in laboratory-based experiments as well as 'in the wild' (Hutchins, 1995). Importantly, by characterising microserendipity as requiring both environmental and personal factors, we can assess the relative contributions of each, and how these interact.

This further constitutes a methodological shift for the study of serendipity from the retrospective description of a phenomenon - currently the dominant methodology of serendipity research - to one that can be observed and categorised independently. This is not to suggest that a third person account is necessarily more reliable (indeed, one of us has argued elsewhere for the opposite [Vallée-Tourangeau \& March, 2019]) but rather that there is currently a dearth of such accounts in the serendipity literature. A combination of both personal reflections and third person observations will likely broaden research horizons and seed theoretical developments. It will further allow us to track the moments when serendipitous affordances in the environment are not exploited through choice but through a form of inattentional blindness (Simons \& Chabris, 1999).

\section{Conclusion}


The role of luck has been a constant yet unexamined refrain in the literature around creativity. While people have examined the luck over the longer time scale of artistic careers and output, there has been little systematic examination of the role of accidents in creativity. This is despite evidence from qualitative data that accidents do in fact frequently play a role in artistic creativity. Luck is, however, by its very nature unpredictable and arbitrary. More suitable to a programme of creative cognition is a framework that accounts for how random environmental affordances and accidents become part of an ecosystem which incorporates both luck and the person or more properly, that is, a framework of serendipity.

The importance of serendipity to discovery and innovation is clear (Foster \& Ford, 2003). Large corporations such as Dreamworks are actively trying to promote serendipitous encounters (Cunha, Clegg, \& Mendonça, 2010; but see also Olma, 2016, wherein he assesses the value of such corporate level serendipity and the inherent dangers in structuring for serendipity). Furthermore, there is a strong thread in the serendipity research literature of looking at the environmental aspects of serendipity that would be useful as a complement to both the insight literature and theorising on 'real world' artistic creativity. While serendipity itself is dependent on accident and chance, subtle shifts in the environment alongside certain personal characteristics may foster serendipity (Björneborn, 2017; McCay-Peet, Toms, \& Kelloway, 2015).

Our understanding of the ontology of both creativity and of serendipity is influenced by the methodologies we use to investigate them. This hampers the understanding of both. We propose that third-person observations of moments of microserendipity will extend our understanding of the role of luck and accident in the creative process and, consequently, their importance to the final product. It will also allow us to catalogue when people do not notice chance as it arises in the environment. Missed serendipity on this scale (unlike say the longer time scale identified in Barber \& Fox, 1958) would be impossible to identify from 
retrospective narratives. This methodological shift is not proposed with the aim to replace other aspects of analysis nor provide an exhaustive explanation of what is a necessarily complex action and process, but rather to support our understanding of how creative thinking and acting proceeds in a complex and situated world, and to begin to disentangle the balance between accident and human agency in creativity. 


\section{References}

Austin, J. H. (1979). The varieties of chance in scientific research. Medical Hypotheses, 5, 737-742.

\section{https://doi.org/10.1016/0306-9877(79)90035-5}

Agnoli, S., Franchin, L., Rubaltelli, E., \& Corazza, G. E. (2015). An eye-tracking analysis of irrelevance processing as moderator of openness and creative performance. Creativity Research Journal, 27(2), 125-132. https://doi.org/10.1080/10400419.2015.1030304

Ball, L. J., \& Litchfield, D. (2013). Interactivity and embodied cues in problem solving, learning and insight: Further contributions to a "Theory of Hints". In S. J. Cowley \& F. Vallée - Tourangeau (Eds.), Cognition beyond the brain (pp. 232-239). Springer.

Barber, B., \& Fox, R. C. (1958). The Case of the Floppy-Eared Rabbits: An Instance of Serendipity Gained and Serendipity Lost. American Journal of Sociology, 64(2), 128136. https://doi.org/10.1086/222420

Bardt, C. (2019) Material and mind. MIT press.

Barad, K. (2003). Posthumanist performativity: Toward an understanding of how matter comes to matter. Signs: Journal of Women in Culture and Society, 28(3), 801-831. https://doi.org/10.1086/345321

Björneborn, L. (2017). Three key affordances for serendipity: Toward a framework connecting environmental and personal factors in serendipitous encounters. Journal of Documentation, 73, 1053-1081. https://doi.org/10.1108/JD-07-2016-0097

Blackburn, S. (2017). Creativity and no-so-dumb luck. In S. Elliot Paul \& S. B. Kaufman (Eds.), The philosophy of creativity: New essays (pp. 147-156). Oxford University Press.

Bogers, T., \& Björneborn, L. (2013). Micro-serendipity: Meaningful coincidences in everyday life shared on Twitter. IConference 2013 Proceedings, 196-208. https://doi.org/10.9776/13175 
Chemero, A. (2011). Radical embodied cognitive science. MIT Press.

Coffman, E. J. (2009). Does luck exclude control? Australasian Journal of Philosophy, 87(3), 499-504. https://doi.org/10.1080/00048400802674677

Copeland, S. (2017). On serendipity in science: Discovery at the intersection of chance and wisdom. Synthese, 196, 2385-2406. https://doi.org/10.1007/s11229-017-1544-3

Csikszentmihalyi, M. (1996). Creativity: The psychology of discovery and invention. Harper Collins.

Cunha, M. P., Clegg, S. R., \& Mendonça, S. (2010). On serendipity and organizing. European Management Journal, 28, 319-330. https://doi.org/10.1016/j.emj.2010.07.001

Danek, A. H. (2018). Magic tricks, sudden restructuring and the aha! experience. In F. Vallée-Tourangeau (Ed.), Insight: On the origin of new ideas (pp. 51-79). Routledge.

Danziger, K. (1985). The methodological imperative in psychology. Philosophy of the Social Sciences, 15, 1-13. https://doi.org/10.1177/004839318501500101

Erdelez, S., Heinström, J., Makri, S., Björneborn, L., Beheshti, J., Toms, E., \& Agarwal, N. K. (2016). Research perspectives on serendipity and information encountering. Proceedings of the Association for Information Science and Technology, 53, 1-5. https://doi.org/10.1002/pra2.2016.14505301011

Fleck, J. I., \& Weisberg, R. W. (2013). Insight versus analysis: Evidence for diverse methods in problem solving. Journal of Cognitive Psychology, 25, 436-463. https://doi.org/10.1080/20445911.2013.779248

Foster, A. E., \& Ellis, D. (2014). Serendipity and its study. Journal of Documentation, 70, 1015-1038. https://doi.org/10.1108/JD-03-2014-0053

Foster, A. E., \& Ford, N. (2003). Serendipity and information seeking: An empirical study. Journal of Documentation, 59, 321-340. https://doi.org/10.1108/00220410310472518 
Glăveanu, V. P. (2012). What can be done with an egg? Creativity, material objects, and the theory of affordances. The Journal of Creative Behavior, 46, 192-208. https://doi.org/10.1002/jocb.13

Glăveanu, V. P. (2014). Distributed creativity: Thinking outside of the box of the individual. Springer.

Glăveanu, V. P., Lubart, T., Bonnardel, N., Botella, M., Biaisi, P.-M. de, Desainte-Catherine, M., ... Zenasni, F. (2013). Creativity as action: Findings from five creative domains. Frontiers in Psychology, 4. https://doi.org/10.3389/fpsyg.2013.00176

Glăveanu, V. P. (2020) A sociocultural theory of creativity: Bridging the social, the material, and the psychological, Review of General Psychology.

Glăveanu, V. P., \& Lahlou, S. (2012). Through the creator's eyes: Using the subjective camera to study craft creativity. Creativity Research Journal, 24(2-3), 152-162. https://doi.org/10.1080/10400419.2012.677293

Hutchins, E. (1995). Cognition in the wild. Cambridge, MA: MIT Press.

Ingold, T. (2009). The textility of making. Cambridge Journal of Economics, 34(1), 91102. doi:10.1093/cje/bep042

Kieran, M. (2017). Creativity as virtue of character. In E. S. Paul \& S. B. Kaufman (Eds.), The philosophy of creativity: New essays (pp. 125-144). Oxford University Press.

Knoblauch, H., Soeffner, H.-G., Raab, J., \& Schnettler, B. (2013). Video analysis: Methodology and methods. Qualitative audiovisual data analysis in sociology. Peter Lang GmbH, Internationaler Verlag der Wissenschaften.

Lahlou, S. (2011). How can we capture the subject's perspective? An evidence-based approach for the social scientist. Social Science Information, 50(3-4), 607-655. https://doi.org/10.1177/0539018411411033 
Makri, S., \& Blandford, A. (2012). Coming across information serendipitously - Part 1: A process model. Journal of Documentation, 68, 684-705. https://doi.org/10.1108/00220411211256030

Malafouris, L. (2020). Thinking as "thinging": Psychology with things. Current Directions in Psychological Science, 29(1), 3-8. https://doi.org/10.1177/0963721419873349

Malafouris, L. (2014). Creative thinging: The feeling of and for clay. Pragmatics $\&$ Cognition, 22(1), 140-158. https://doi.org/10.1075/pc.22.1.08mal

March, P. L. (2019). Playing with clay and the uncertainty of agency. A Material Engagement Theory perspective. Phenomenology and the Cognitive Sciences, 18, 133151.

McCay-Peet, L., \& Toms, E. G. (2015). Investigating serendipity: How it unfolds and what may influence it. Journal of the Association for Information Science and Technology, 66, 1463-1476. https://doi.org/10.1002/asi.23273

McCay-Peet, L., Toms, E. G., \& Kelloway, E. K. (2015). Examination of relationships among serendipity, the environment, and individual differences. Information Processing \& Management, 51, 391-412. https://doi.org/10.1016/j.ipm.2015.02.004

Merton, R., \& Barber, E. (2004). The travels and adventures of serendipity: A study in sociological semantics and the sociology of science. Princeton University press.

Montuori, A., \& Purser, R. E. (1995). Deconstructing the lone genius myth: Toward a contextual view of creativity. Journal of Humanistic Psychology, 35, 69-112.

Napolitano, C. M. (2013). More than just a simple twist of fate: Serendipitous relations in developmental science. Human Development, 56, 291-318.

https://doi.org/10.1159/000355022 
Ohlsson, S. (1992). Information-processing explanations of insight and related phenomena. In M. T. Keane \& K. J. Gilhooly (Eds.), Advances in the psychology of thinking (pp. 144). Harvester Wheatsheaf.

Olma, S. (2016). In defence of serendipity. Repeater.

Orlikowski, W. J. (2007). Sociomaterial practices: Exploring technology at work. Organization Studies, 28(9), 1435-1448. https://doi.org/10.1177/0170840607081138 Piñeyro, A. (2019). Kinetic morphologies. Revealing opportunity from mistake. The Design Journal, 22(sup1), 1871-1882. https://doi.org/10.1080/14606925.2019.1595027

Race, T. M., \& Makri, S. (Eds.). (2016). Accidental information discovery: Cultivating serendipity in the digital age. Elsevier : Chandos Publishing.

Ross, W., \& Vallée-Tourangeau, F. (2020). Catch that word: Interactivity, serendipity and verbal fluency in a word production task. Psychological Research. https://doi.org/10.1007/s00426-019-01279-y

Ross, W., \& Vallée-Tourangeau, F. (under review). Making your own luck: A mixed methods study disentangling luck and serendipity in anagram solving.

Rubin, V. L., Burkell, J., \& Quan-Haase, A. (2011). Facets of serendipity in everyday chance encounters: A grounded theory approach to blog analysis. Information Research, 16. https://doi.org/[Available at http://InformationR.net/ir/16-3/paper488.html]

Robinson, O. (2011). The idiographic/nomothetic dichotomy: Tracing historical origins of contemporary confusions. History \& Philosophy of Psychology, 13(2), 32-39.

Sawyer, R. K. (2010). Individual and group creativity. In J. C. Kaufman \& R. J. Sternberg (Eds.), The Cambridge Handbook of Creativity (pp. 366-380). Cambridge University Press.

Sawyer, R. K. (2018). How artists create: An empirical study of MFA painting students. The Journal of Creative Behavior, 52, 127-141. https://doi.org/10.1002/jocb.136 
Schubert, C. (2013). Video analysis of practice and the practice of video analysis. In H. Knoblauch, H.-G. Soeffner, J. Raab, \& B. Schnettler (Eds.), Video analysis: Methodology and methods qualitative audiovisual data analysis in sociology. Peter Lang GmbH, Internationaler Verlag der Wissenschaften. http://nbnresolving.de/urn:nbn:de:101:1-201311054294

Simons, D. J., \& Chabris, C. F. (1999). Gorillas in our midst: Sustained inattentional blindness for dynamic events. Perception, 28, 1059-1074.

Simonton, D. (2004). Creativity in science: Chance, logic, genius, and zeitgeist. Cambridge University Press.

Sjöholm, J. (2014). The art studio as archive: Tracing the geography of artistic potentiality, progress and production. Cultural Geographies, 21, 505-514. https://doi.org/10.1177/1474474012473060

Steffensen, S. V., Vallée-Tourangeau, F., \& Vallée-Tourangeau, G. (2016). Cognitive events in a problem-solving task: A qualitative method for investigating interactivity in the 17 Animals problem. Journal of Cognitive Psychology, 28, 79-105.

\section{https://doi.org/10.1080/20445911.2015.1095193}

Sutton, J. (2010). Exograms and interdisciplinarity: History, the extended mind, and the civilising process. In R. Menary (Ed.), The extended mind (pp. 189-227). MIT Press.

Tanggaard, L., \& Beghetto, R. A. (2015). Ideational pathways: Toward a new approach for studying the life of ideas. Creativity. Theories - Research - Applications, 2(2), 129144. https://doi.org/10.1515/ctra-2015-0017

Vallee-Tourangeau, F. (2014). Insight, interactivity and materiality. Pragmatics \& Cognition, 22, 27-44. https://doi.org/10.1075/pc.22.1.02val

Vallée-Tourangeau, F., \& March, P. L. (2019). Insight out: Making creativity visible. The Journal of Creative Behavior, 1-19. https://doi.org/10.1002/jocb.409 
Vallée-Tourangeau, F., Steffensen, S. V., Vallée-Tourangeau, G., \& Sirota, M. (2016). Insight with hands and things. Acta Psychologica, 170, 195-205. https://doi.org/doi: 10.1016/j.actpsy.2016.08.006

Vallée-Tourangeau, F., \& Vallée-Tourangeau, G. (2020). Mapping systemic resources in problem solving. New Ideas in Psychology. https://doi.org/10.1016/j.newideapsych.2020.100812

Van Andel, P. (1994). Anatomy of the unsought finding. The British Journal for the Philosophy of Science, 45, 631-648.

Weisberg, R. W. (2006). Creativity: Understanding innovation in problem solving, science, invention and the arts. Wiley.

Weisberg, R. (2010). The study of creativity: From genius to cognitive science. International Journal of Cultural Policy, 16, 235-253. https://doi.org/10.1080/10286630903111639

Weisberg, R. W. (2015). On the usefulness of "value" in the definition of creativity. Creativity Research Journal, 27, 111-124. https://doi.org/10.1080/10400419.2015.1030320

Wheeler, M. (2018) Talking about more than heads/; the embodied, embedded and extended creative mind in B. Gaut \& M. Kieran (Eds.) Creativity and philosophy,(pp. 230 -25). Routledge.

Yaqub, O. (2018). Serendipity: Towards a taxonomy and a theory. Research Policy, 47, 169179. https://doi.org/10.1016/j.respol.2017.10.007 


\section{Facets of Serendipity in Everyday Chance Encounters}

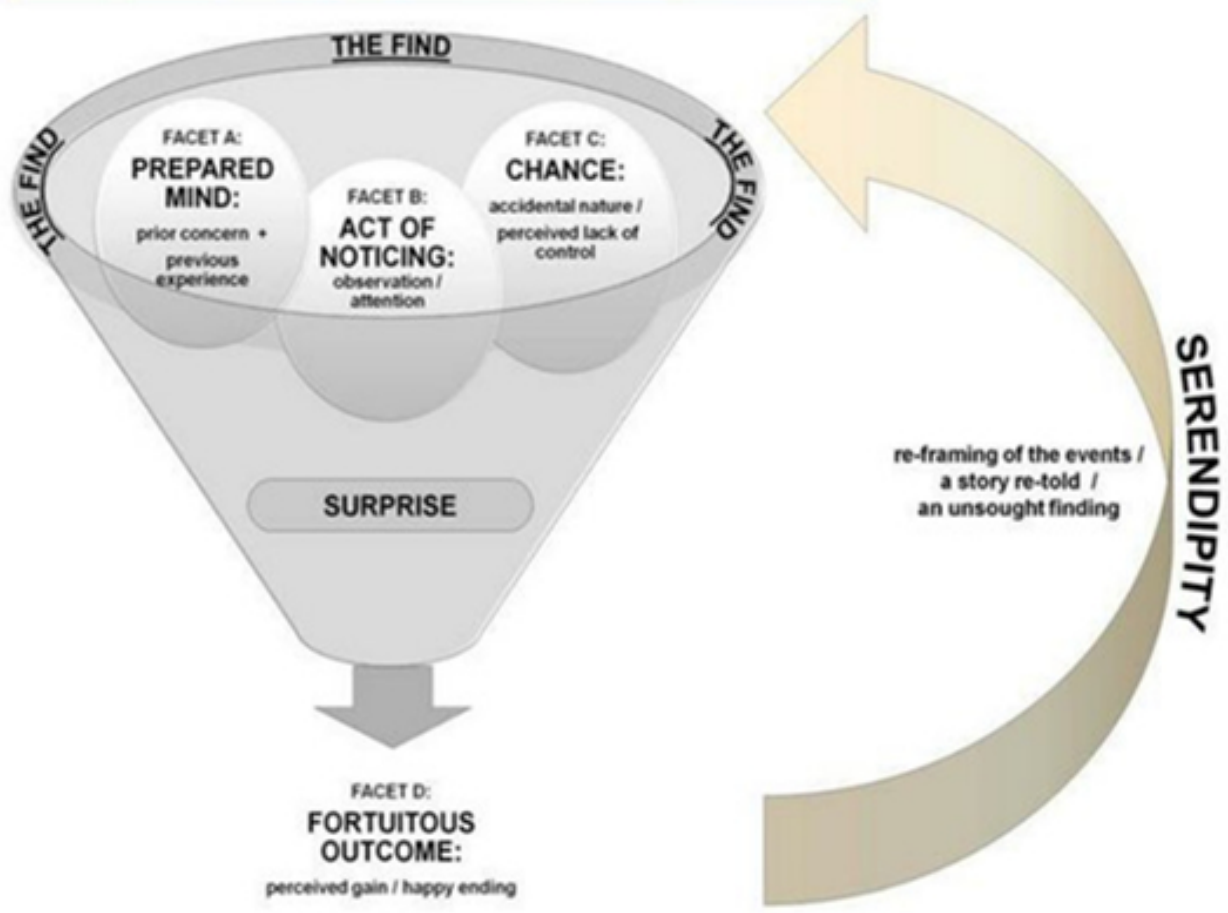

'Facets of Serendipity in Everyday Chance Encounters' (Taken From Rubin et al. 2011)

$93 \times 75 \mathrm{~mm}(150 \times 150 \mathrm{DPI})$ 


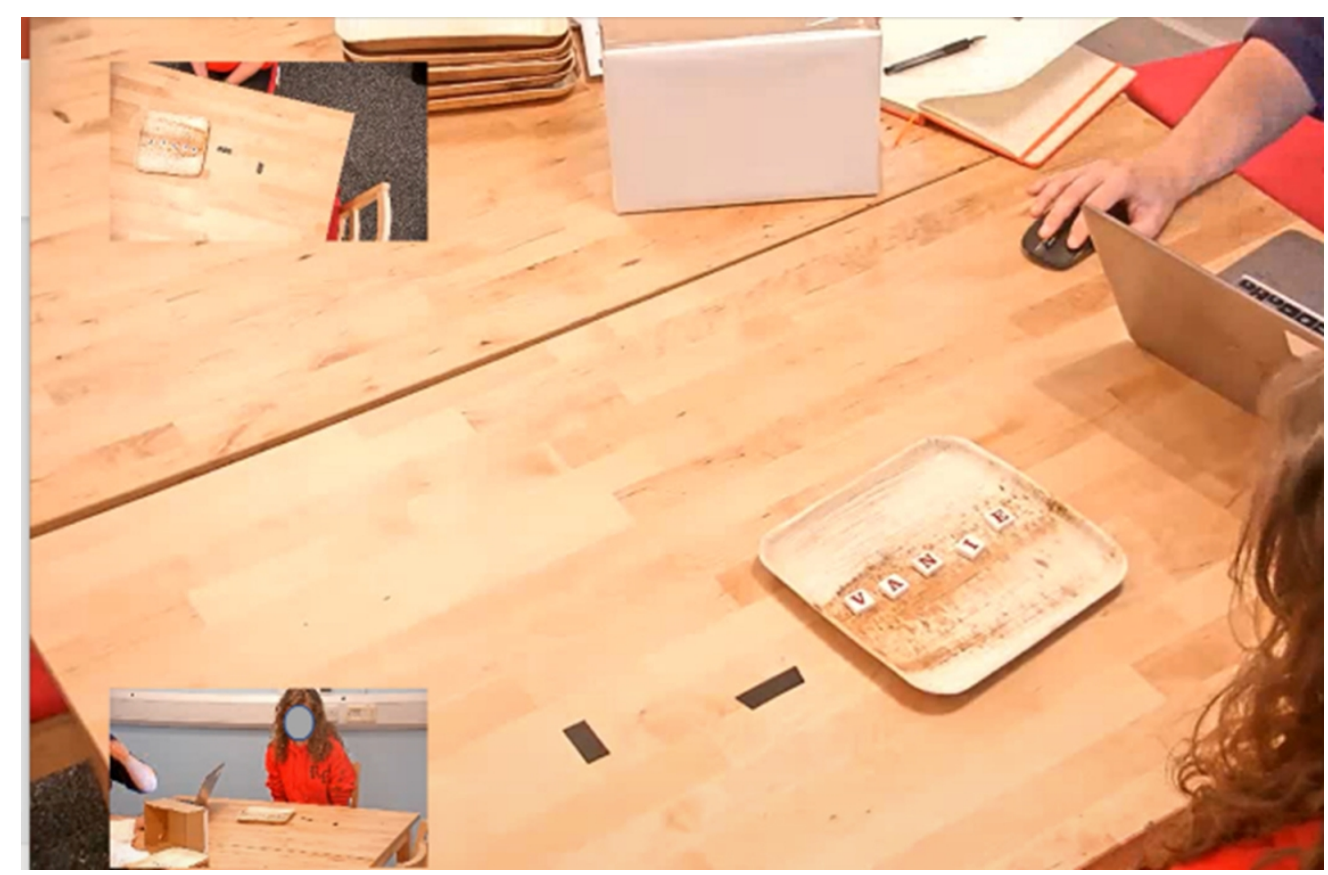

The Observation Laboratory and Camera Angles for the Anagram Solving Study Reported in Ross and ValléeTourangeau (under review).

$165 \times 108 \mathrm{~mm}(220 \times 220$ DPI $)$ 